\title{
A New Method for Preparation of Xylobiose, Eliminating Xylose from Enzymatic Xylan Hydrolyzate by Yeast ${ }^{\dagger}$
}

\author{
Isao KuSAKABE, Tsuneo Yasui and Tatsuyoshi Kobayashi \\ Laboratory of Wood Hydrolysis and Fermentation, Faculty of Agriculture, \\ Tokyo University of Education, Komaba-cho, Meguro-ku, Tokyo
}

Received October 24, 1974

\begin{abstract}
Establishment of a new method for preparation of xylobiose was investigated.
When hardwood xylan was hydrolyzed by the xylanase system of Streptomyces sp. E-86, the hydrolyzate mainly consisted of xylose and xylobiose in an approximate ratio of $1: 1$.

Yeast strains selected in this paper, effectively and selectively metabolized all of xylose without any degradation of xylobiose.

By successive treatments of xylan with Streptomyces xylanase system and xylose-metabolizable yeast, $70.4 \mathrm{~g}$ of crystalline xylobiose was obtained from $172 \mathrm{~g}$ of xylan.
\end{abstract}

Xylobiose $^{1,2)}$ has been obtained from the partial hydrolyzates of various hemicellulose (for example, from corncobs and rice straw). However, this ordinary preparation method has not been applicable for yielding substantial quantity of xylobiose, because of low yield and complexity in operation.

In this paper, we deal with an establishment of a novel and effective method for the preparation of xylobiose from xylan.

\section{MATERIALS AND METHODS}

Microorganisms. Strain E-86 of Streptomyces was used throughout this work, which was isolated from soil and maintained on Bennet's agar slant at room temperature. The strain formed a large clear zone when grown on the xylan agar plate.

Yeast strains used were originated in the collection of IFO (Institute for Fermentation, Osaka, Japan), IAM (Institute of Applied Microbiology, University of Tokyo, Japan), AHU (Faculty of Agriculture, Hokkaido University, Japan), NI (Nagao Institute, Tokyo, Japan) and our laboratory (K-number), and maintained on the malt yeast-extract agar slants at room temperature.

Xylan. A commercial hardwood xylan was supplied by the Sanyô-Kokusaku Pulp Company, which was

$t$ Studies on Xylanase System of Streptomyces. Part II.

This work was presented at the Annual Meeting of the Agricultural Chemical Society of Japan, held in Nagoya, April 2, 1968. a by-product from mercerization process of rayon or staple fiber manufacturing and actually insoluble in water.

Xylobiose. Xylobiose was prepared from the hydrolysis products of the xylan by the Streptomyces xylanase, ${ }^{31}$ using the charcoal column chromatography, ${ }^{4 !}$ followed by concentration and crystallization.

Determination of sugar. The amount of reducing sugar was determined by Somogyi's method ${ }^{51}$ and Willstätter-Schudel's method ${ }^{6}$ throughout this work and represented as $\mathrm{mg}$ of xylose. This value was designated as direct reducing sugar. The amount of total reducing sugar was determined by the same method after hydrolysis with $4 \% \mathrm{H}_{2} \mathrm{SO}_{4}$ at $100 \mathrm{C}$ for $2 \sim 2.5 \mathrm{hr}$ and represented as $\mathrm{mg}$ of xylose.

Preparation of enzyme solution. The culture filtrate of Streptomyces sp. E-86 in a xylan-containing medium was used as enzyme solution (see result).

Determination of xylanase activity. The xylanase activity was measured as follows. The reaction mixture containing $70.3 \mathrm{mg}$ (equivalent to $50 \mathrm{mg}$ of anhydroxylose) of crude xylan, $4 \mathrm{ml}$ of Mcllvaine buffer solution (pH 5.70) and $5 \mathrm{ml}$ of water in a L-form tube was preincubated at $55^{\circ} \mathrm{C}$ for $15 \mathrm{~min}$. Reaction was started by addition of $1 \mathrm{ml}$ of the enzyme solution (1/10 dilution) to the reaction mixture, and incubation was continued at $55^{\circ} \mathrm{C}$ on a Monod skaker (Ohtake Seisakusho, Japan). After incubation for $30 \mathrm{~min}, 1 \mathrm{ml}$ of the mixture was drawn and added to $5 \mathrm{ml}$ of Somogyi's reagent in a test tube. The test tube was kept in a boiling water bath for $15 \mathrm{~min}$, then, the reducing sugar was determined as xylose. The xylanase activity was expressed as " $\mathrm{mg}$ of xylose $/ 10 \mathrm{ml}$ of reaction mixture/ 
30 min." The linear relationship between the amount of enzyme and the increase of reducing power of the reaction mixture was not observed, therefore, the activity was calculated from a standard curve previously prepared." The activity showing $8.7 \mathrm{mg}$ was defined as 10 units. $^{71}$

Extent of hydrolysis of xylan and average degree of polymerization of liquefied xylan. The reaction mixture was centrifuged to remove remained xylan, and the supernatant solution obtained (liquefied xylan solution) was then hydrolyzed in $4 \% \mathrm{H}_{2} \mathrm{SO}_{4}$ at $100^{\circ} \mathrm{C}$ for $2 \sim$ $2.5 \mathrm{hr}$. The reducing sugar in the hydrolyzate of the supernatant was estimated as xylose, and the amount was designated as total liquefied xylan. The extent of hydrolysis of xylan was obtained as a ratio of the total liquefied xylan to the original xylan (total xylose). Average degree of polymerization (D.P.) of liquefied xylan was obtained as a ratio of the total reducing sugar to the direct reducing sugar.

Paper chromatography. An appropriate amount (about $0.01 \mathrm{ml}$ containing $30 \sim 150 \mu \mathrm{g}$ of xylose) of sugar solution was spotted on a Tôyô filter paper No. $51(400 \mathrm{~mm} \times 400 \mathrm{~mm})$ and chromatographed at $25^{\circ} \mathrm{C}$ for $20 \sim 25 \mathrm{hr}$ with a solvent system of $n$-butanol: pyridine: water $(6: 4: 3 \mathrm{v} / \mathrm{v})$. After removal of solvent, spot of reducing sugar was developed by spraying $p$ anisidine- $\mathrm{HCl}$ solution in $n$-butanol and heating at $130 \sim 140^{\circ} \mathrm{C}$ for $10 \mathrm{~min}$.

\section{RESULTS}

Production of xylanase system from Streptomyces sp. E-86

The medium ( $\mathrm{pH}$ 5.3) for cultivation of Streptomyces sp. E-86 was composed of xylan $2 \%$, peptone (Daigoeiyô Kagaku, Japan) $1.4 \%$, yeast extract (Daigoeiyô Kagaku, Japan) $0.1 \%$, corn steep liquor $0.5 \%, \mathrm{KH}_{2} \mathrm{PO}_{4} 1.0 \%$, $\mathrm{MgSO}_{4} \cdot 7 \mathrm{H}_{2} \mathrm{O} \quad 0.05 \%$ and a small amount of Tôshiba Silicone as defoamer. Twelve liters of the medium was placed in a 20-liter Jar fermentor (Waldhof type) and sterilized by thermal supply through a heating coil. After cooling, an amount of $200 \mathrm{ml}$ of seed culture, which had been grown in the same medium in shake flasks at $35^{\circ} \mathrm{C}$ for about one day on a reciprocal shaker, was inoculated to the Jar fermentor. The cultivation was carried out at $35 \sim 37.5^{\circ} \mathrm{C}$ with an air supply at a flow rate of 7 liters per min and with an agitation at a speed rate of $540 \mathrm{rpm}$. Figure 1

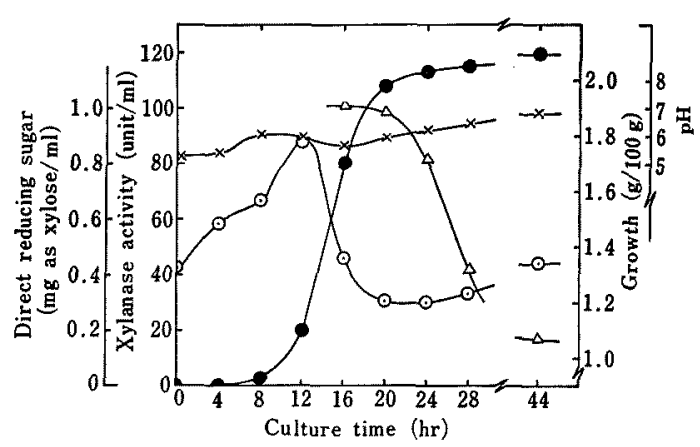

FIG. 1. Time Course of Xylanase Production.

The experimental conditions are described in the text. $\odot-\odot$, direct reducing sugar; -0 , xylanase activity; $\triangle-\triangle$, mycelia weight; $\times-\times, \mathrm{pH}$.

shows the time course of the cultivation. The xylanase activity in the culture filtrate reached a maximum at $24 \sim 28-\mathrm{hr}$ cultivation. After $28 \mathrm{hr}$, the mycelium was filterd off through Buchner funnel, and the culture filtrate was used as the xylanase solution without any treatment. The enzyme solution showed an activity of 115 units $/ \mathrm{ml}$.

\section{Thermal stability of the xylanase system}

The enzyme solution (at $\mathrm{pH}$ 5.7) was treated in water baths at intervals of $5^{\circ} \mathrm{C}$ from $40^{\circ} \mathrm{C}$ to $70^{\circ} \mathrm{C}$, then, quickly cooled in ice water. The residual activities were assayed. As shown in Fig. 2, the enzyme solution retained about

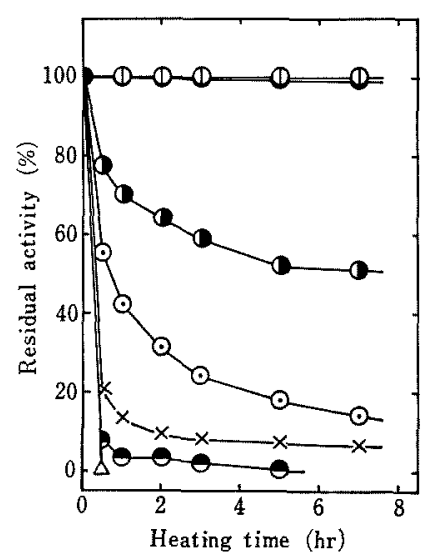

FIG. 2. Thermal Stability of Xylanase System.

The experiment was performed as described in the text. $(1-1), 40^{\circ} \mathrm{C} ; \bigcirc-0,45^{\circ} \mathrm{C} ; \bigcirc-50^{\circ} \mathrm{C} ; \bigcirc-\odot, 55^{\circ} \mathrm{C}$; $x-x, 60^{\circ} \mathrm{C} ; \theta-\Theta, 65^{\circ} \mathrm{C} ; \triangle-\Delta, 70^{\circ} \mathrm{C}$. 
$100 \%$ of the activity after the treatment at $40^{\circ} \mathrm{C}$ to $45^{\circ} \mathrm{C}$ for $7 \mathrm{hr}$, and $23 \%$ of the activity was lost by the treatment at $50^{\circ} \mathrm{C}$ for $30 \mathrm{~min}$. Heating at $70^{\circ} \mathrm{C}$ for $30 \mathrm{~min}$ showed a complete loss of the activity.

Effect of $p H$ and temperature on the direct reducing sugar forming-activity

At $55^{\circ} \mathrm{C}$, the optimum $\mathrm{pH}$ for the xylanase activity was around 5.7 (Fig. 3).

At pH 5.7, the xylanase activity was effected by temperature as shown in Fig. 4-1. The higher the temperature is, the greater the rate of the activity becomes, in early stage of the reaction, such as 30-min incubation. After 24-hr incubation, the highest value of the direct reducing sugar was observed at $55^{\circ} \mathrm{C}$. Furthermore, Fig. 4-2 shows that the hydrolyzate obtained at $35 \sim 60^{\circ} \mathrm{C}$ was mainly composed of xylose and xylobiose, but a significant amount of xylotriose was formed during the hydrolysis at $65 \sim 70^{\circ} \mathrm{C}$. These chromatographic results correspond to D.P. values (presented in parenthesis of Fig. 4-1) of hydrolysis products.

Liquefaction of xylan by the xylanase system under optimum conditions

The time course of the liquefaction under the optimum condition ( $\mathrm{pH} 5.7$ and $55^{\circ} \mathrm{C}$ ), is shown in Fig. 5-1. A few $\mathrm{ml}$ of the reaction mixture was occationally withdrawn from the vessel and was centrifuged as soon as possible at $5^{\circ} \mathrm{C}$. Direct and total reducing sugars in the supernatant were estimated by Somogyi's and Willstätter-Schudel's methods. After 8-hr incubation, the xylan was liquefied almost completly, and D. P. of the hydrolysis products (liquefied xylan) decreased to 1.50. However, as shown in paper chromatograms (Fig. 5-2), a considerable amount of higher oligomers than dimer remained in the hydrolysis products. After incubation for $20 \sim 24 \mathrm{hr}$, the final products were found to be consisted of xylose and xylobiose in approximately equal amounts, without contamination with detectable amount of other xylooligomers. D.P. value of the products was decreased to 1.35 .
Exclusive elimination of xylose from xylosexylobiose mixture by the activity of yeast The yeasts, which are able to metabolize

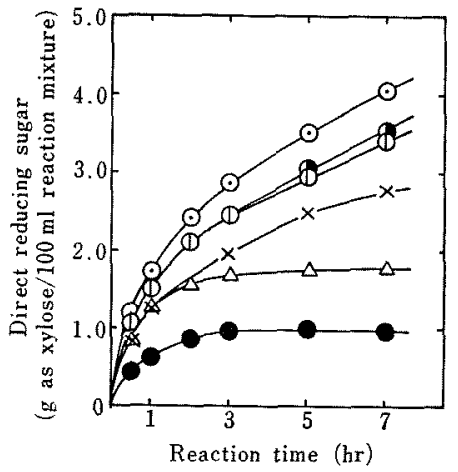

FIG. 3. Effect of $\mathrm{pH}$ on the Direct Reducing Sugarforming Activity of the Xylanase System.

The composition of the reaction mixture was $1 \mathrm{~g}$ of xylan, $3 \mathrm{ml}$ of water and $4 \mathrm{ml}$ of McIlvaine buffer solution of various $\mathrm{pH}$ values. After preincubation, $2 \mathrm{ml}$ of the enzyme solution $(115 \mathrm{U} / \mathrm{ml})$ was added to the reaction mixture and incubated at $55^{\circ} \mathrm{C}$ continually. An aliquot of reaction mixture was removed in 0.5 , $1,2,3,5$ and $7 \mathrm{hr}$ and the direct reducing sugar was determined as xylose.

- $-\mathrm{pH} 3.62 ; \triangle-\triangle, \mathrm{pH} 4.30 ; \quad-\mathrm{a}, \mathrm{pH} 5.07$; $\odot-\odot$, pH $5.70 ;(1-1$, pH $6.05 ; \times-\times$, pH 6.80 .

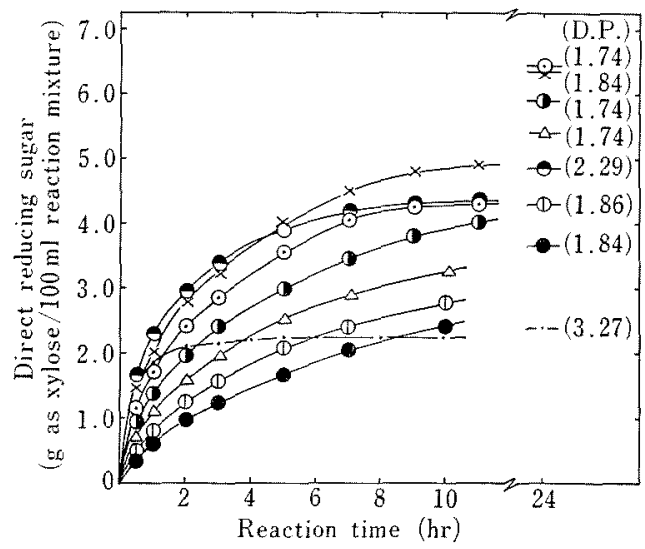

Fig. 4-1. Effect of Temperature on the Direct Reducing Sugar-forming Activity of the Xylanase System.

The composition of the reaction mixture: $2.0 \mathrm{~g}$ of xylan, $8 \mathrm{ml}$ of Mcllvaine buffer solution ( $\mathrm{pH} 5.70$ ), $6 \mathrm{ml}$ of water and $4 \mathrm{ml}$ of the enzyme solution (115 $\mathrm{U} / \mathrm{ml}$ ). The reaction mixture was incubated at the various temperature under $\mathrm{pH}$ value of 5.70 .

$-0,35^{\circ} \mathrm{C} ;(1)-(1), 40^{\circ} \mathrm{C} ; \triangle-\triangle, 45^{\circ} \mathrm{C} ; 0-50^{\circ} \mathrm{C}$; $\odot-55^{\circ} \mathrm{C} ; \times-\times, 60^{\circ} \mathrm{C} ;--6,65^{\circ} \mathrm{C} ; \cdots-70^{\circ} \mathrm{C}$. 


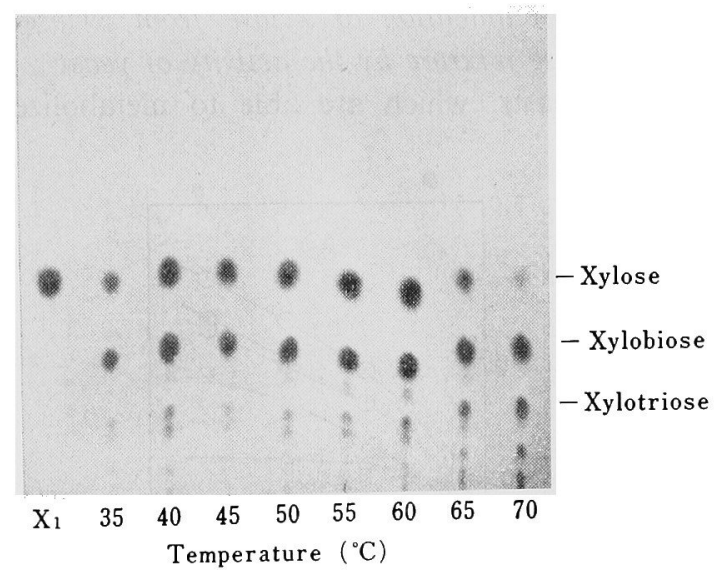

FIG. 4-2. Paper Chromatograms of Xylan Hydrolyzates by the Xylanase System from Streptomyces sp. E-86.

The experimental condition and samples were the same as in Fig. 4-1 (reacted for $24 \mathrm{hr}$ ).

$\mathrm{X}_{1}$ : authentic xylose.

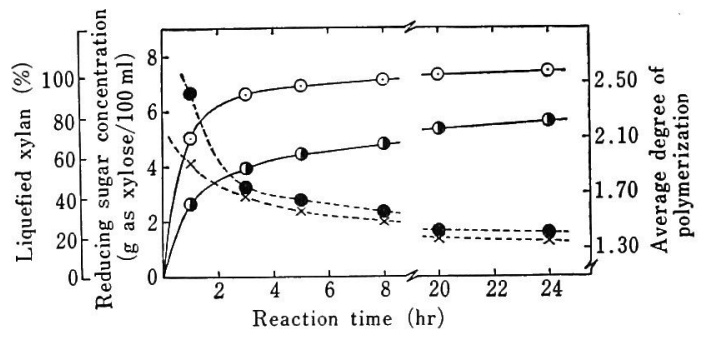

FIG. 5-1. Liquefaction of Xylan by Xylanase System.

The reaction mixture was composed of $117 \mathrm{~g}$ of xylan ( $86 \mathrm{~g}$ as anhydroxylose), $100 \mathrm{ml}$ of tap water and $1200 \mathrm{ml}$ of the enzyme solution $(115 \mathrm{U} / \mathrm{ml})$. The mixture was incubated at $55^{\circ} \mathrm{C}$ in a $1500 \mathrm{ml}$ glass beaker with agitation of $200 \mathrm{rpm}$. Throughout saccharification, $\mathrm{pH}$ was maintained at 5.7 by addition of $\mathrm{NaOH}$ solution.

$\odot-\odot$, total reducing sugar or liquefied xylan; - - direct reducing sugar.

Average degree of polymerization:

---. Willstätter-Schugel's method.

$\{\times---\times$, Somogyi's method.

exclusively xylose and to leave xylobiose without any loss, were selected from the collection in our laboratory. These are Candida parapsilosis var. komabaensis K-75, Candida pulcherrima NI 7477, Pichia halophila, Geotrichum species and others. When the cells of the first four strains were grown in medium containing xylose, all strains consumed completely

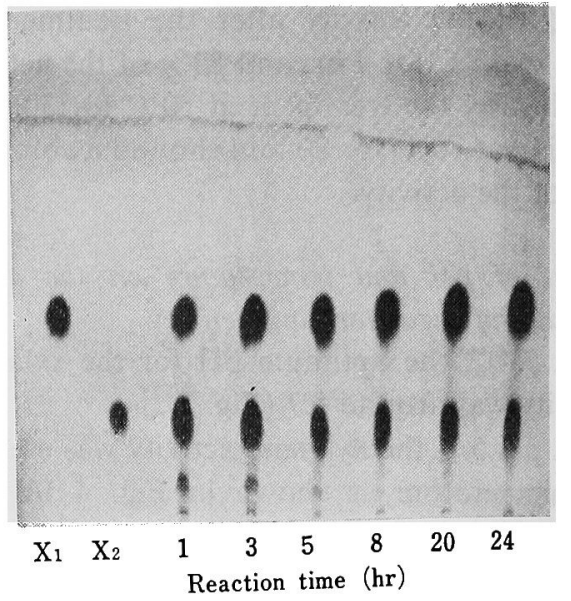

FIG. 5-2. Paper Chromatograms of Xylan Hydrolyzates by the Xylanase System.

The samples were same ones in Fig. 5-1.

$\mathrm{X}_{1}$, authentic xylose; $\mathrm{X}_{2}$, authentic xylobiose.

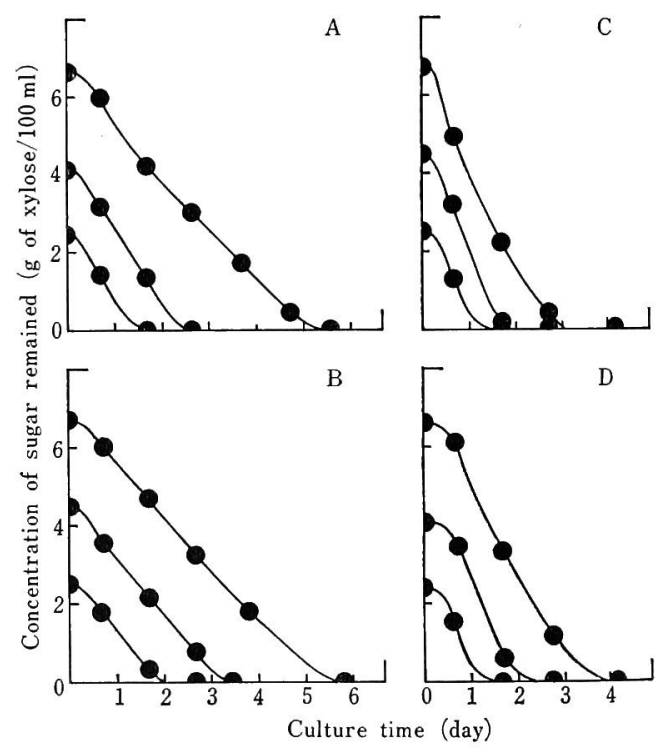

Fig. 6. Consumption of Xylose by Several Yeast. The medium was composed of xylose $2.5 \sim 6.5 \%$, peptone $0.4 \%$, yeast extract $0.1 \%, \mathrm{KH}_{2} \mathrm{PO}_{4} 0.1 \%$ and $\mathrm{MgSO}_{4} \cdot 7 \mathrm{H}_{2} \mathrm{O} 0.05 \%$. Each $100 \mathrm{ml}$ of the medium was placed into $500 \mathrm{ml}$ of shake flasks and sterilized. Two $\mathrm{ml}$ of seed culture grown on the same medium was inoculated to it and cultivated at $30^{\circ} \mathrm{C}$ on reciprocal shaker. A: Geotrichum 58, B: Geotrichum 61, C: Candida pulcherrima NI 7477, D: Candida parapsilosis var. komabaensis $\mathrm{K}-75$.

xylose within 6 days (Fig. 6). Among the yeasts tested, $C$. parapsilosis and $C$. pulcherrima could eliminate xylose in rather high concentra- 


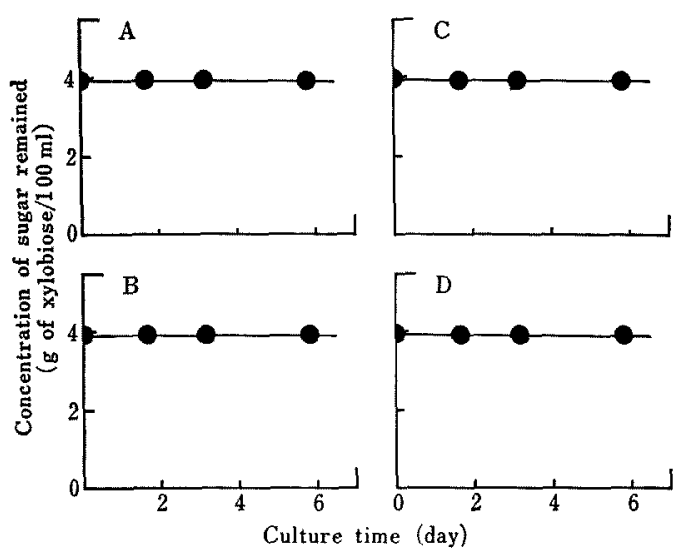

FIG. 7. Non-assimilability of Xylobiose by the Yeasts Tested.

The medium was composed of xylobiose $4 \%$, peptone $0.4 \%$, yeast extract $0.1 \%, \mathrm{KH}_{2} \mathrm{PO}_{4} 0.1 \%$ and $\mathrm{MgSO}_{4}$. $7 \mathrm{H}_{2} \mathrm{O} 0.05 \%$. Experimental condition was the same as shown in Fig. 6.

A: Geotrichum 58, B: Geotrichum 61, C: Candida pulcherrima NI 7477, D: Candida parapsilosis var. komabaensis $\mathrm{K}-75$.

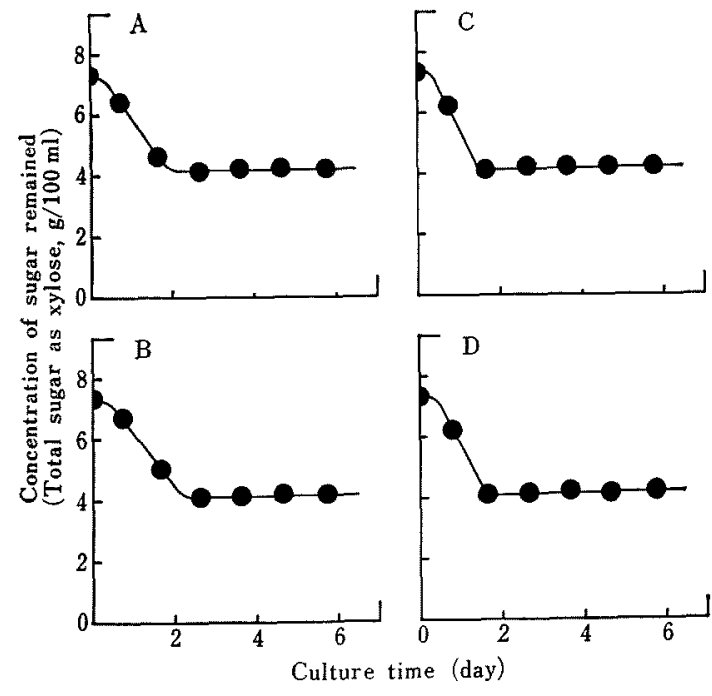

FIG. 8. Elimination of Xylose from Mixture of Xylose and Xylobiose by Several Xylose-assimilating Yeasts.

The medium consisted of xylose $3.2 \%$, xylobiose $3.9 \%$ and other nutrients as shown in Fig. 6 . Experimental condition was as shown in Fig. 6 also.

A: Geotrichum 58, B: Geotrichum 61, C: Candida pulcherrima NI 7477, D: Candida parapsilosis var. komabaensis $\mathrm{K}-75$.

tions at a high speed. As seen in Fig. 7, all the yeasts tested did not assimilate xylobiose at all under the condition described in Fig. 6. When these strains were grown in a medium composed of $3.2 \%$ of xylose, $3.9 \%$ of xylobiose and nutritional supplements, they could degradate completely xylose after 2 days without any loss of xylobiose (Fig. 8). For long period of incubation, the concentration of total sugar (xylobiose) and D.P. of sugar in the culture filtrates remained constant.

For the practical purpose, the elimination of xylose from the enzymatic hydrolyzate of xylan was examined with 2 yeast strains, $C$. parapsilosis and $C$. pulcherrima. Time course of elimination of xylose is summarized in Figs. 9-1 and 9-2. When both organisms were cultured in the hydrolyzate-media containing $7.4 \%$ of total reducing sugar (D. P. 1.35), the concentration of the total reducing sugar was decreased to about $4 \%$ after 2 days, and remained constant through further incuba-

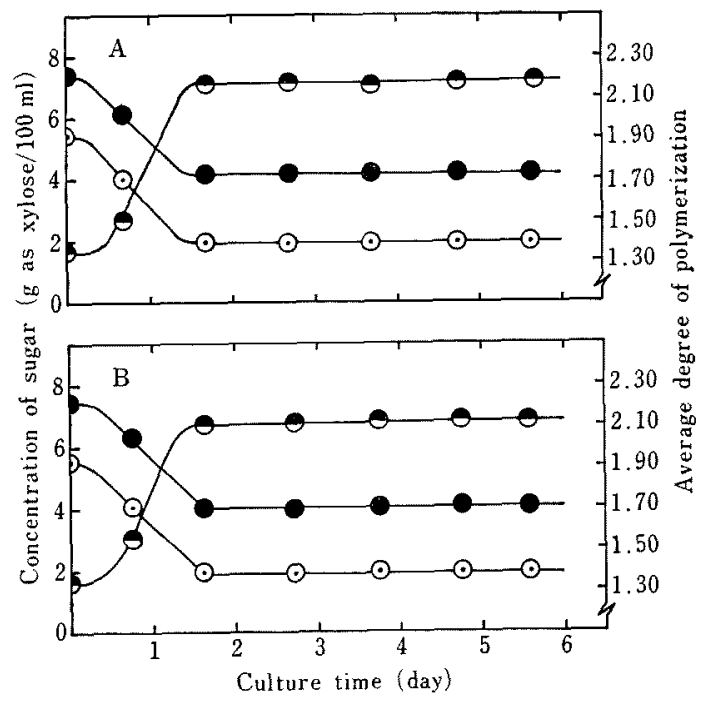

Fig. 9-1. Elimination of Xylose from Enzymatic Hydrolyzate of Xylan by the Xylose-utilizable Yeasts.

The medium was composed of peptone $0.4 \mathrm{~g}$, yeast extract $0.1 \mathrm{~g}, \mathrm{KH}_{2} \mathrm{PO}_{4} 0.1 \mathrm{~g}, \quad \mathrm{MgSO}_{4} \cdot 7 \mathrm{H}_{2} \mathrm{O} 0.05 \mathrm{~g}$ in $100 \mathrm{ml}$ of enzymatic hydrolyzate (pH 5.7$)$ in $500 \mathrm{ml}$ of shake flasks. Seed cultures were inoculated to the medium and cultivation was performed at $30^{\circ} \mathrm{C}$ on a reciprocal shaker.

A: Candida pulcherrima NI 7477,

$\mathrm{B}$ : Candida parapsilosis var. komabaensis $\mathrm{K}-75$.

$\odot-\odot$, direct reducing sugar (as xylose); - - , total reducing sugar (as xylose); - - - , average degree of polymerization. 

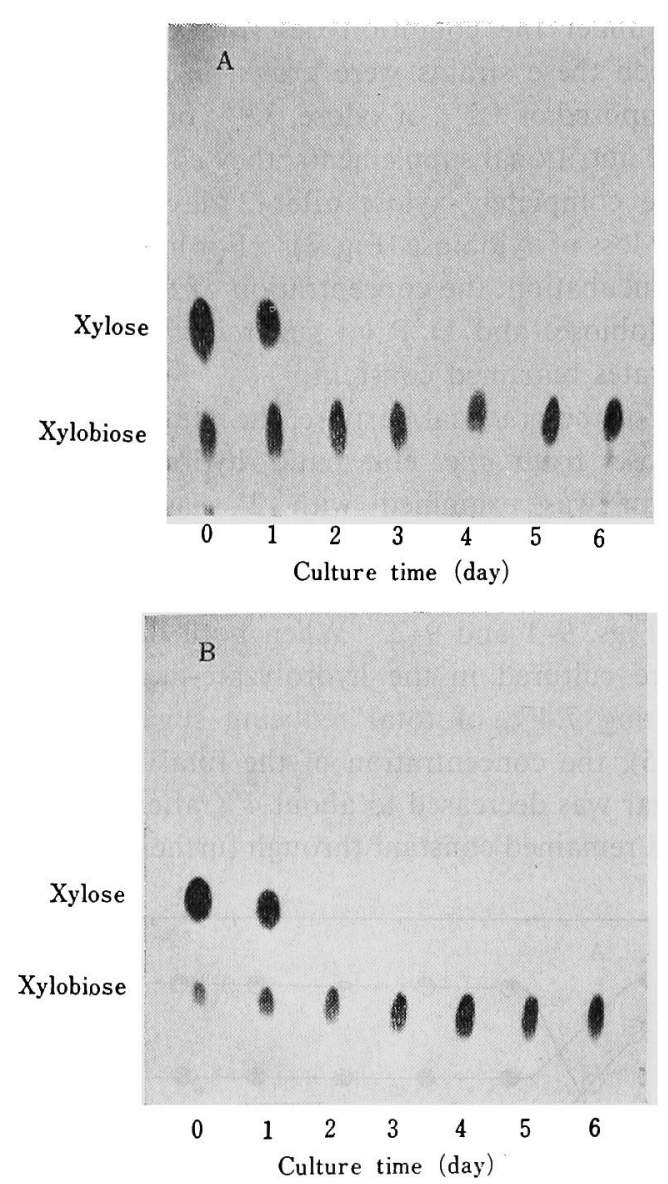

FIG. 9-2. Elimination of Xylose from Hydrolyzate by Several Xylose-assimilating Yeasts.

Samples were derived from the culture broths shown in Fig. 9-1. A: Candida pulcherrima NI 7477, B: Candida parapsilosis var. komabaensis $\mathrm{K}-75$.

tion. The activities of both strains were almost the same.

Preparation of xylobiose

Actually, xylan (equivalent to $172 \mathrm{~g}$ of anhy- droxylose) was hydrolyzed by $2400 \mathrm{~g}$ of the solution of Streptomyces xylanase according to the procedure described above. After the removal of insoluble fractions by centrifugation from the hydrolyzate, $2619 \mathrm{~g}$ of clear solution containing $200 \mathrm{~g}$ of total xylose was obtained. The solution was supplemented with nutrients, sterilized, inoculated with a seed culture of the yeasts, $C$. parapsilosis, and aerobically incubated at $30^{\circ} \mathrm{C}$ for 2.5 days. After the incubation, the yeast cells were discared by centrifugation, thus, $2400 \mathrm{~g}$ of the supernatant solution containing $100.7 \mathrm{~g}$ of total xylose was obtained. The solution was decolorized with carbon, followed by deionization by treatment with the columns of cation (IR-200) and anion (IRA-68) exchange resins. The treated solution was concentrated under reduced pressure. Xylobiose $(70.4 \mathrm{~g})$ was crystallized from the concentrated solution at room temperature. The flow sheet for preparation of xylobiose is summarized in Fig. $10-1$.

Properties of xylobiose prepared and its acetyl derivative

Crude crystal of xylobiose obtained was twice recrystallized from about $85 \%$ aqueous ethanol. The recrystallized xylobiose was paper-chromatographycally pure, and 2.0 of D. P. which was determined by WillstätterSchudel's method. The xylobiose was acetylated with anhydrous sodium acetate and acetic anhydride mixture according to the method of Whistler et al., ${ }^{8)}$ and its acetyl derivative was recrystallyzed from ethanol. Their properties are summarized in Table I, in comparison with the data of Whistler et al. ${ }^{87}$

Table I. Some Properties of Xylobiose Obtained and Its Hexaacetate Arrows indicate mutarotatory property.

\begin{tabular}{ccccc}
\hline & \multicolumn{2}{c}{ Xylobiose } & \multicolumn{2}{c}{ Xylobiose hexaacetate } \\
\hline & $\begin{array}{c}\text { Obtained here } \\
\text { (Recrystallized) }\end{array}$ & $\begin{array}{c}\text { From data } \\
\text { of Whistler }{ }^{1,2)}\end{array}$ & $\begin{array}{c}\text { Obtained here } \\
\text { (Recrystallized) }\end{array}$ & $\begin{array}{c}\text { From data } \\
\text { of Whistler }{ }^{8)}\end{array}$ \\
\hline$[\alpha]_{\mathrm{D}}^{25}$ & $\begin{array}{c}-34.5 \rightarrow-25.0 \\
(c=2.0 \text { in water })\end{array}$ & $\begin{array}{c}-32.0 \rightarrow-25.5 \\
(c=1 \text { in water })\end{array}$ & $\begin{array}{c}-73.8 \\
\left(c=1.0 \text { in } \mathrm{CHCl}_{3}\right)\end{array}$ & $\left(c=0.9\right.$ in $\left.\mathrm{CHCl}_{3}\right)$ \\
\hline Melting point $\left({ }^{\circ} \mathrm{C}\right)$ & $187 \sim 189$ & $186 \sim 187$ & $154.4 \sim 155.1$. & $154 \sim 155$ \\
\hline
\end{tabular}




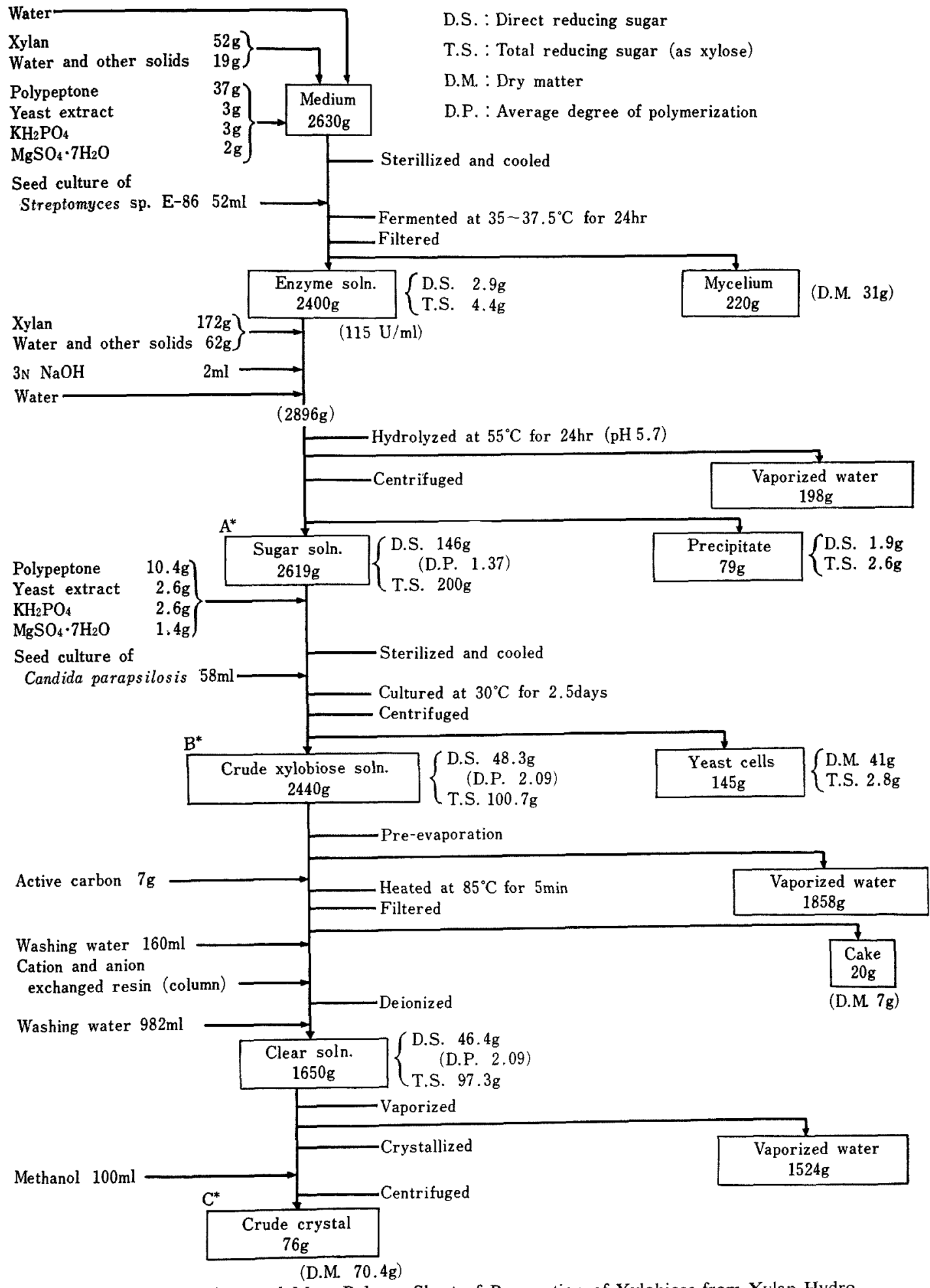

FIG. 10-1. Procedure and Mass Balance Sheet of Preparation of Xylobiose from Xylan Hydrolyzate Using Candida parapsilosis var. komabaensis $\mathrm{K}-75$.

$\mathrm{A}^{*}, \mathrm{~B}^{*}, \mathrm{C}^{*}$ refer to ones in Fig. 10-2. 


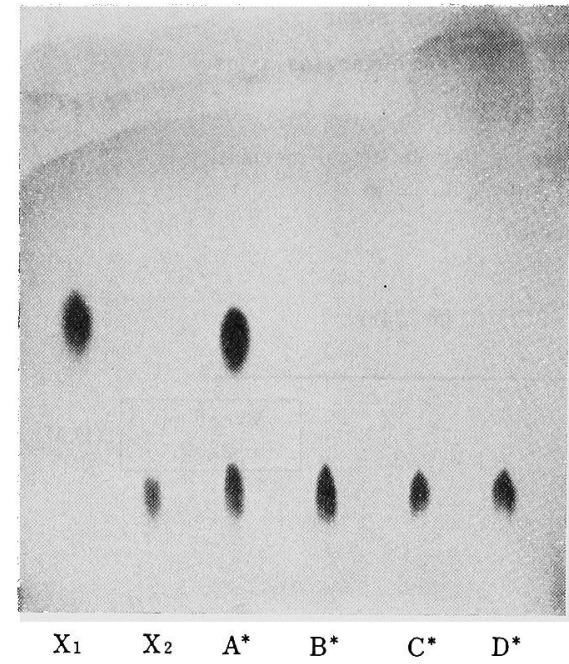

FIG. 10-2. Paper Chromatograms of Sugar Samples in Various Stages of Xylobiose Preparation.

$\mathrm{X}_{1}$, authentic xylose; $\mathrm{X}_{2}$, authentic xylobiose; $A^{*}$, xylan hydrolyzate by the xylanase system of Streptomyces sp. E-86; B*, A* after treatment with Candida parapsilosis var. komabaensis $\mathrm{K}-75$; $\mathrm{C}^{*}$, crude crystal of xylobiose; $\mathrm{D}^{*}$, xylobiose recrystallized from $85 \%$ ethanol. $\mathrm{A}^{*}, \mathrm{~B}^{*}, \mathrm{C}^{*}$, in this figure correspond to $\mathrm{A}^{*}, \mathrm{~B}^{*}, \mathrm{C}^{*}$, in Fig. 10-1.

\section{DISCUSSION}

Hydrolyzate of hardwood xylan by the Streptomyces xylanase system was composed of xylose and xylobiose in an approximate ratio of $1: 1$ with small amount of contaminants of other oligosacchrides. Xylanase system producing exclusively xylobiose from xylan have never been known. Hardwood xylan contains a small amount of glucuronide residue as a minor component in addition to a large amount of xylose residue (unpublished data), therefore, a small of a glucuronide-containing oligosaccharides should be present in the hydrolyzate. However, these minor components did not interfere the preparation of crystalline xylobiose. For separation of sugars the chromatographical technique is very effective, therefore, microbiological method including the selective fermentation with certain yeast has little application. However, in the case of simple sugar composition, especially composed of only two sugars, the selective fermentation method may be very convenient for obtaining a special sugar in a relatively large quantity. In our case, selected yeasts had a satisfactory nature, that is, they could assimilate only xylose, but they had no assimilability against xylobiose at all. We could successfully adopt the characteristic nature of the Streptomyces xylanase system and the speciality in sugar assimilability of yeasts in this procedure.

\section{REFERENCES}

1) R. L. Whistler and C. C. Tu, J. Am. Chem. Soc., 73, 1389 (1951).

2) R. L. Whistler and C. C. Tu, ibid., 74, 3609 (1952).

3) I. Kusakabe, T. Yasui and T. Kobayashi, Nippon Nôgeikagaku Kaishi, 43, 145 (1969).

4) R. L. Whistler and D. F. Durso, J. Am. Chem. Soc., 72, 677 (1950).

5) M. Somogyi, J. Biol. Chem., 160, 61 (1945).

6) R. Willstätter and G. Schudel, Ber., 51, 780 (1918).

7) I. Kusakabe, T. Yasui and T. Kobayashi, $J$. Ferment. Technol., 53, 135 (1975).

8) R. L. Whistler and C. C. Tu, J. Am. Chem. Soc., 74, 4334 (1952). 